Stoa

Vol. 1, No. 2, 2010, pp. 53-60.

ISSN: 2007-1868

\title{
RÉPLICA A “LA PERSISTENCIA DEL YO” DE RODRIGO GUERRA
}

\author{
Adolfo García de la Sienra \\ Instituto de Filosofía \\ Universidad Veracruzana \\ asienrag@gmail.com
}

RESUMEN: En su artículo "La persistencia del yo: ensayos sobre la inmortalidad del alma" ( en este volumen) Rodrigo Guerra presenta una serie de argumentos en favor de la inmortalidad del alma. Esta réplica asevera que dichos argumentos son convincentes sólo para aquellos para quienes las premisas son admisibles. Como la admisibilidad de las premisas depende del motivo religioso que anima al escucha, se concluye que los argumentos carecen de efectividad apologética.

PALABRAS CLAVE: inmortalidad del alma, apologética, filosofía de la mente.

SUMMARY: In his article "La persistencia del yo: ensayos sobre la inmortalidad del alma" (this volumen) Rodrigo Guerra offers a series of arguments in favor of the immortality of the soul. This reply claims that such arguments are convincing only to those for whom the premises are admissible. Since the admissibility of the premises depends upon the religious motive that impels the audience, the conclusion is that the arguments lack apologetic effectivity.

KEY WORDS: immortality of the soul, apologetics, philosophy of mind.

\section{Introducción}

Es desde luego una enseñanza de la religión cristiana que el alma, espíritu o ego del hombre es inmortal. La Escritura enseña esto en muchos pasajes y el mismo ministerio de Jesucristo carecería de sentido si no lo fuera. Aquellos que admiten la Escritura como verdadera, como palabra revelada por Dios, no tienen ningún problema para admitir dicha enseñanza, por lo que cabría preguntarse qué objeto tiene proveer argumentos filosóficos en su favor "al margen de una fe religiosa”, por lo cual entiendo al margen de cualquier motivo 
religioso. ${ }^{1}$ Pero la pregunta no es principalmente si ello es útil o necesario; la pregunta es, sobre todo, si es ello posible. Afirmar su posibilidad implica sostener que es posible encontrar un cuerpo de evidencia admisible bajo cualquier cosmovisión. ¿Es ello posible?

\section{Pablo en Atenas}

El libro de los Hechos (17:16-34) narra la recepción que tuvo el mensaje del Evangelio entre los filósofos epicúreos y estoicos, quienes invitaron al apóstol Pablo a que explicara en el Areópago la "nueva enseñanza" de que hablaba. Los presentes escucharon con atención el discurso (22-31) hasta que Pablo hizo mención de la resurrección de los muertos. Relata la Escritura que en ese momento, cuando oyeron lo de la resurrección de los muertos, "unos se burlaban y otros decían: Ya te oiremos acerca de esto otra vez. Yasí Pablo salió de enmedio de ellos" (32-33).

La razón por la que el mensaje de la resurrección resultó completamente inaceptable a muchos de los presentes en el Areópago fue que estaban dominados por un motivo religioso que impide siquiera vislumbrar el concepto escritural de alma. En efecto, el hombre no puede ver de sí mismo más allá de lo que puede ver en su ídolo; un motivo religioso básico apóstata fuerza al hombre a verse en la imagen de su ídolo.

Por esta razón, la "sicología" griega nunca concibió la unidad religiosa radical del hombre y nunca penetró en lo que es verdaderamente llamado el "alma”, el centro religioso de la existencia humana. Cuando el motivo materia dominó el pensamiento griego, el alma fue vista meramente como un principio vital informe e impersonal, atrapado en el flujo de la vida. El motivo materia no reconoció la "inmortalidad individual". La muerte era el fin del hombre como un ser individual. Su fuerza vital era destruida, de tal modo que el ciclo de la vida pudiera continuar. (Dooyeweerd 1998, p. 34)

Desde luego la religión griega de la materia siempre afirmó que la justicia, la diké consistía en la desaparición de toda forma individual, para que se afirmase como únicamente divino el interminable flujo de la vida: el ciego destino, la anangké, condenaba ineluctablemente a toda forma individual a dejar de

\footnotetext{
${ }^{1}$ Para una caracterización precisa del concepto de motivo religioso, véase Dooyeweerd 1998,
} capítulo 1. 
ser para siempre, así como las olas del mar, que pasan y nunca regresan las mismas.

\section{La clausura de la fe}

Decimos que la función religiosa de la fe dentro del marco de una cosmovisión está más cerrada entre más abajo en la cadena de modalidades de la realidad se encuentre la cualidad más alta del ídolo que gobierna la cosmovisión; es decir, en modalidades como la aritmética, la geométrica, la física o la biótica. ${ }^{2} \mathrm{Si}$ la cualidad definitoria del ídolo es de carácter físico, por ejemplo, el hombre no puede imaginarse a sí mismo como teniendo una cualidad mayor que la física.

Desde luego, la estructura misma de la realidad introduce tensiones en los motivos religiosos. Es una ley general que la divinización de un aspecto de la realidad genera un motivo religioso dialéctico bipolar. En el caso particular de la conciencia griega antigua, la divinización de la materia condujo a la divinización de su "antítesis", la forma. Esto significó la apertura de la fe hacia modalidades más elevadas en la cadena: modalidades culturales como la lógica o la jurídica, conduciendo a la idea de que la finalidad más alta del hombre era la de ser un ciudadano libre de la polis. Al divinizar el pensamiento lógico, la ideas, Platón introdujo la concepción de un topos ouranos. Su noción de episteme como reminiscencia lo forzó a concebir algo inmortal en el hombre, razón por la cual algunos teólogos cristianos lo han considerado como una especie de precursor de la fe. ${ }^{3}$ Sin embargo, las premisas de un argumento platónico en pro de la inmortalidad del alma sólo serían aceptables a alguien que estuviera de acuerdo con él en que las ideas son eternas y el conocimiento reminiscencia.

No se puede negar que una fe apóstata de pueblos paganos, que eventualmente se volvieron líderes en la historia del mundo, sufrió un proceso de apertura después de un periodo inicial de una primitiva y difusa "creencia de naturaleza". Este proceso estuvo directamente relacionado con el hecho de que tales pueblos fueron más allá de sus condiciones culturales más o menos primitivas. Entre los griegos, por ejemplo, observamos una transición clara de las religiones de la naturaleza originales primitivas, que adoraban el flujo impersonal e informe de la vida, a una religión de la cultura, en la que los dioses se convirtieron en potencias culturales idealizadas

${ }^{2}$ Sobre el concepto de modalidad de la experiencia, véase García de la Sienra 1995.

${ }^{3}$ Cfr. Juan Calvino, Institución de la religión cristiana, libro I, capítulo XV, $\$ 6$. 
con forma y configuración personal suprahumana. En este proceso de desarrollo y apertura, la religión apóstata trascendió la creencia primitiva en la naturaleza y se orientó a la revelación de Dios en los aspectos normativos de la realidad temporal. Dando forma cultural a su fe idólatra, el hombre caído empezó a concebir a sus dioses como configuraciones personales idealizadas. Conducida por este desarrollo de la fe, la norma de diferenciación histórica empezó a operar en el desarrollo cultural griego. Esto estuvo a su vez acompañado por una individualización de la cultura, la cual tuvo lugar en la más abarcante comunidad cultural nacional. (Dooyeweerd, 1998, p. 107)

La tesis escritural que estos ejemplos ilustran es precisamente la de que, debido a la caída, el hombre no puede alcanzar el conocimiento de sí mismo, ya que el autoconocimiento es completamente dependiente del conocimiento de Dios. A lo sumo, una fe apóstata abierta hacia los aspectos normativos de la creación alcanzará cierta noción del alma humana que puede sugerirle que ésta tiene que ser inmortal. El argumento filosófico en ese caso sólo puede tener la misión de mostrar de qué manera la visión del ego permitida por el motivo religioso subyacente es compatible o de alguna manera implica o sugiere la inmortalidad del mismo.

\section{El destinatario del argumento de Guerra}

Cabe preguntar, pues, ¿̇a quién va dirigido el argumento de Rodrigo Guerra? Me parece bastante claro que en el Areópago hubiera sido encontrado como muy poco convincente. Creo que los griegos dominados por el motivo de la Madre Tierra, o cierta clase de materialistas actuales (como los postmodernos nietzscheanos, por ejemplo, dominados por el motivo religioso griego bajo una nueva guisa) encontrarán sus premisas como falsas. Consideremos una por una.

1. El yo es persistente. Aduce Guerra una razón de persistencia: parece patente que el yo "se encuentra presente en unidad durante toda la experiencia simultánea de sentir, pensar, escoger, etc.”. Parece que hasta un materialista reconocería en su experiencia dicha unidad y permanencia. Sin embargo, lo que diría es que esa permanencia es el resultado de la "injusticia" de esta forma individual (un hombre) que insiste en perseverar en la existencia manteniéndose contra el flujo de la vida. Para el materialista, es este flujo el verdaderamen- 
te persistente, y el ciego destino ha condenado ya, ineluctablemente, a dicha forma a perecer.

2. El yo es absolutamente indivisible de manera real o matemática. El materialista diría que sí, mientras tiene existencia. No aceptaría que tiene simplicidad.

3. El yo es insustituible. El materialista diría que sí, que los yos nuevos que aparecen en la recurrencia del ciclo de la vida son numéricamente distintos de los que ya han perecido; los que han perecido nunca retornarán ya: en eso consiste precisamente la diké. De hecho, dirían que cualquier forma individual es metafísicamente induplicable.

4. El yo posee capacidad de abstracción. Esto es difícil de negar, sobre todo debido a las capacidades del habla, las cuales serían imposibles sin una cierta capacidad de generalización, de abarcar diversos entes bajo un mismo término o concepto.

5. El yo descubre lo que es inmaterial y eterno de algún modo. Aquí Guerra parece estar admitiendo una especie de platonismo, al suponer que las proposiciones de la lógica y las matemáticas son eternas. Desde luego, los materialistas tienen problemas para explicar las verdades de la lógica y las matemáticas, pero no es necesario suponer que sean eternas para admitir su validez universal, ya que son tan eternas como los objetos de que tratan. De hecho, afirmar la eternidad de ideas u objetos matemáticos entra en contradicción con el monoteísmo, el cual afirma que Dios es creador de todas las cosas, visibles e invisibles. Estoy seguro de que Guerra suscribe el monoteísmo. No obstante, algo nos está diciendo acerca de las capacidades del hombre el solo hecho de que pueda descubrir este tipo de verdades e incluso razonar rigurosamente sobre ellas. Presupone una apertura de la función de la fe hacia una modalidad más alta que la psíquica.

6. La vivencia de la felicidad exige inmortalidad. Este es un argumento curioso que Kant habría criticado. Una versión caricaturizada sería: tengo hambre, por lo tanto debe haber comida. Sin embargo, la caricatura puede voltearse en favor del argumento. La misma existencia del hambre está apuntando hacia una necesidad real constitutiva del hombre. En efecto, es un hecho que las personas estiman la perspectiva de la propia muerte como una limitación a 
la felicidad que pueden estar sientiendo en un momento determinado. Surge la cuestión de por qué, si la muerte es tan natural, habría el alma humana de sentirse infeliz por ella. Nadie se siente desdichado de que el agua sea transparente, pero sí de la muerte propia o de la de los seres queridos. Creo que este es en efecto el argumento más fuerte de los que Guerra aporta en este texto.

7. La libertad es incompatible con la dependencia respecto de procesos cerebrales. Aquí Guerra suena muy kantiano, al decirnos que "el acto libre implica autoposesión que contradice radicalmente la dependencia causal absoluta de la conciencia respecto de las leyes que regulan el mundo material". Ésta se antoja como una definición muy absolutista de libertad. El acto libre más bien parece consistir en la capacidad de elegir entre opciones presentes, pero siempre bajo las restricciones que las leyes y normas que rigen la creación imponen. ¿En qué sentido puede ser la conciencia absolutamente independiente de las leyes que rigen el mundo material? Es una petición de principio decir que la conciencia no depende del cerebro para hacer elecciones; más bien parecería lo contrario. Por lo demás, la independencia en el sentido de no tomar en cuenta las leyes y normas para hacer elecciones parece una receta segura para el desastre. El ego tiene que ser conciente de las restricciones que las leyes naturales le imponen a sus decisiones.

Lo que sí es interesante observar es la capacidad del hombre para trascender la inmanencia y mirar hacia la eternidad. Por lo menos las religiones que creen en una divinidad trascendente - el judaísmo, el cristianismo y el islam- tendrían que aceptar que el hombre posee tal capacidad. Pero ello sería difícil de entender si el espíritu del hombre no trascendiese, en algún sentido, la inmanencia, la temporalidad. Esa trascendencia sugiere que el espíritu del hombre no está esencialmente atado a la temporalidad. Pero una fe cerrada, volcada hacia las modalidades inferiores, como es el materialismo, no tendría por qué estar de acuerdo con que el hombre tiene tal capacidad en lo absoluto.

8. La inmortalidad es una exigencia de la vida moral del yo. En este argumento resuena nuevamente la ética de Kant, la cual requiere, para armonizar la felicidad con el deber, de la inmortalidad del alma: el deber, en final ajuste de 
cuentas, conduce a la felicidad. Si esa felicidad no se encuentra en una vida presente entregada al deber, debe encontrarse en la otra.

9. El alma no puede ser aniquilada por el mal moral. Este argumento sería la versión "secularizada" del que sigue.

10. El alma no puede ser aniquilada por el pecado. Desde luego, la Escritura sí que habla de la muerte espiritual (Efesios 2:1), pero ese concepto de muerte no significa la inexistencia o inactividad permanente del espíritu, sino más bien su dirección apóstata. Cuando el Señor Jesucristo dice que no temamos a los que matan el cuerpo, mas el alma no pueden matar, sino que temamos más bien a aquel que puede destruir el alma y el cuerpo en el infierno (Mateo 10:28), obviamente no está diciendo que el alma pueda ser aniquilada, sino más bien lo contrario, que será sujetada a sufrimientos que en algún sentido la destruyen. El concepto de pecado es intrínseco a las religiones de origen judaico o tipo bíblico y su uso difícilmente cabe dentro de una argumento que pretenda ser religiosamente neutral.

11. El amor demanda comunión sin término. Este punto se conecta con el 6. Desde luego, la experiencia de la muerte de los seres queridos es un trauma que nos planta frente a esta realidad. Se pueden repetir las mismas consideraciones que se hicieron en relación con 6 . Este argumento tiene una cierta solidez. Pues, si el hombre está hecho para el amor, particularmente para amar a Dios sobre todas las cosas y disfrutar eternamente de la comunión con Él, hay cierta disonancia en la creencia de que la muerte es la última verdad.

En suma, creo que los argumentos de Guerra sirven para afianzar en el cristiano creencias que brotan naturalmente de la fe que profesa, pero la aceptación de su validez reside en la aceptación de la verdad de las premisas. El problema es que aquellos que profesan una religión cuya divinidad no es trascendente no pueden aceptar las premisas (quizá con excepción de la 6 y la 11). Pero entonces el argumento no puede tener usos apologéticos para aquellos que no estaban ya previamente convencidos de sus conclusiones.

\section{Referencias}

Calvino, Juan, 1994, Institución de la religión cristiana, Fundación Editorial de Literatura Reformada, Rijkswijk. 
Dooyeweerd, H., 1998, Las raíces de la cultura occidental, Clie, Barcelona.

García de la Sienra, A., 1995, "El ente y su naturaleza”, en Diánoia 1994, UNAM/Fondo de Cultura Económica, México, pp. 37-51.

Recibido el 1 de marzo 2010

Aceptado el 1 de abril 2010 